\title{
The double glucagon test, a new liver function test
}

\author{
H. VERHAEGEN \\ M.D. \\ M. L. VerhaEgen-DeclercQ \\ M.D. \\ A. DE BEUKELAER \\ M.D. \\ F. KRUG
M.D.
}

\section{Summary}

A double glucagon test was performed in 100 patients and seventeen control subjects. Two intravenous doses of glucagon (1 $\mathrm{mg}$ ) were administered at a 1-hr interval. Glucose was determined before the first injection and 20, 25 and $30 \mathrm{~min}$ after both doses, and the increases after each successive dose were added up.

In normal persons, the total increase in glycaemia was higher in the second than in the first hour and reached at least $110 \mathrm{mg}$. Normal values were found in cases of obstructive jaundice, cholelithiasis and adult diabetes, and abnormal values in patients with infective hepatitis, liver congestion and cirrhosis.

The double glucagon test was found to be very useful for the differential diagnosis of liver cell impairment and hepatic obstruction.

\section{Introduction}

Glucagon increases hepatic glycogenolysis by activating the phosphorylating enzymes by which glycogen is converted into glucose (Sutherland \& Cori, 1951; Van Itally \& Bentley, 1955). Considering that the glycogen content of the diseased liver is usually low and that glucagon apparently does not induce muscular glycogenolysis but only hepatic. glycogenolysis, the possibility of a new liver functiono test was envisaged.

\section{Subjects}

The study included 100 patients (fifty-three me $\frac{9}{1}, \frac{1}{2}$ and forty-seven women, age range 20-74 years), mest of them with jaundice. Their diagnoses are pres sented in Table 1 and some additional informationise given below. In three of the patients with obstructirejaundice the symptoms lasted for several weefs. Two of the patients with acute hepatitis displayed af cholestatic component with marked increase in? alkaline phosphatase. Four of the nine patients with cholelithiasis had cholecystitis, but none of themp suffered from obstructive jaundice. Patients with hepatic precoma were excluded because of the risko of severe hypoglycaemia which might speed the onset of coma.

In addition, a control group of seventeen persons was selected. All of them were free from hepatic

TABLE 1. Results of the double glucagon test in various diagnostic categories and in a control population. Minimum, maximum and mean increases in $\mathrm{mg} / \mathrm{ml}$ in the first $\left(\Sigma_{1}\right)$ and second $\left(\Sigma_{2}\right)$ test as compared with the pre-glucagon control levelsi and the number of instances in which $\Sigma_{2}$ was lower or higher than $\Sigma_{1}$

\begin{tabular}{|c|c|c|c|c|c|c|c|c|c|}
\hline \multirow{2}{*}{ Diagnoses } & \multirow{2}{*}{$\begin{array}{c}\text { Number } \\
\text { of } \\
\text { patients }\end{array}$} & \multicolumn{3}{|c|}{$\Sigma_{1}$} & \multicolumn{3}{|c|}{$\Sigma_{2}$} & \multirow{2}{*}{$\Sigma_{1}>\Sigma_{2}$} & \multirow{2}{*}{$\Sigma_{1}<\Sigma_{2}$} \\
\hline & & Min & $\operatorname{Max}$ & Mean & Min & $\operatorname{Max}$ & Mean & & \\
\hline Control group & 17 & 96 & $2 \mathrm{CO}$ & 136 & 110 & 240 & 160 & 0 & $16^{*}$ \\
\hline
\end{tabular}

* One case: $\Sigma_{1}=\Sigma_{2}$. 
disease and had normal serum flocculation tests, bromsulphtalein and serum transaminases.

\section{Method}

The tests were performed in the morning after a 14-hr fasting period. Two intravenous doses of $1 \mathrm{mg}$ of glucagon were given at an interval of $1 \mathrm{hr}$. Capillary blood samples were taken, by finger prick, $5 \mathrm{~min}$ and immediately before the first injection, and 20,25 and $30 \mathrm{~min}$ after the first and second injection. The capillary blood glucose $(\mathrm{mg} / \mathrm{ml})$ at the six postglucagon determinations was compared, for each subject, with the control level (average of the two pre-glucagon samples). The sum of the increases after each injection indicated the 'total hyperglycaemia' in the first $\left(\Sigma_{1}\right)$ and second $\left(\Sigma_{2}\right)$ hour. Blood glucose was determined by the NelsonSomogyi method (Nelson, 1944).

\section{Results}

The results for the various diagnostic categories and the control group are presented in the accompanying table.

In the control group, the mean average increase in glycaemia was $136 \mathrm{mg}$ (range 96-200) in the first hour and $160 \mathrm{mg}(110-240)$ in the second hour. In sixteen subjects $\Sigma_{2}$ was higher than $\Sigma_{1}$ and in one subject $\Sigma_{2}$ was equal to $\Sigma_{1}$.

A normal response to glucagon was observed in the patients with obstructive jaundice even when the disease had been present for several weeks.

In patients suffering from infective hepatitis, $\Sigma_{1}$ was lower than in the control group and the overlap was very slight. $\Sigma_{2}$ was always lower than in the control population and usually lower than $\Sigma_{1}$ (Fig 1A).

Similar results were achieved in patients with cirrhosis; the overlap was somewhat larger than in the patients suffering from hepatitis and two patients displayed a normal double-glucagon test (Fig. 1B).

The difference was statistically highly significant $(P<0.0001)$ for $\Sigma_{1}, \Sigma_{2}$ and $\Sigma_{2}-\Sigma_{1}$ between the control group and the patients with hepatitis, and for $\Sigma_{1}$ and $\Sigma_{2}$ between the controls and the patients with cirrhosis.

Patients with hepatic congestion due to heart failure showed low $\Sigma_{1}$, and $\Sigma_{2}$ was lower than $\Sigma_{1}$ in all instances. Patients with liver metastases had similar low values in the two tests and $\Sigma_{2}$ was lower than $\Sigma_{1}$ in six of eight cases. As several patients were rather cachectic at the time of the test, malnutrition may have interfered with the results.
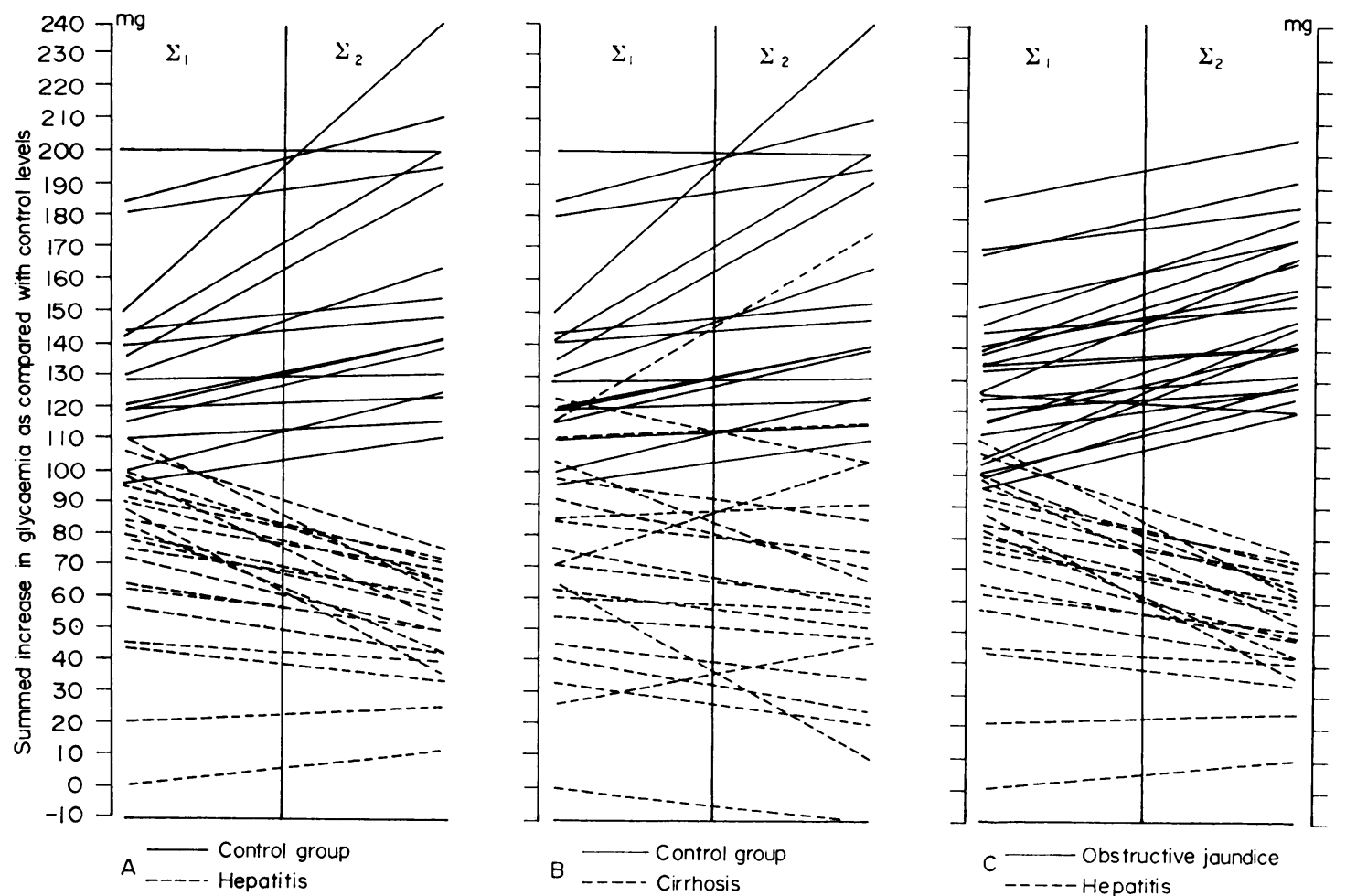

Fig. 1. Individual results of the double glucagon test. Summed increase in glycaemia after the first ( $\left.\Sigma_{1}\right)$ and second $\left(\Sigma_{2}\right)$ injection of $1 \mathrm{mg}$ glucagon. 
Neither cholelithiasis nor stable diabetes had any influence on either $\Sigma_{1}$ or $\Sigma_{2}$, the results of the tests being very similar to those in the control group.

\section{Discussion and conclusion}

In the control group, the response to intravenous glucagon is higher after the second than after the first dose. This is probably due to the double action of glucagon on the production of glucose: a glycogenolytic action of rapid onset and a gluconeogenic effect starting after about one hour (Exton et al., 1966). Thus the increase in blood glucose, in the second hour, is the sum of the glycogenolytic effect of the second injection and the gluconeogenic effect of the first. This hypothesis will be further investigated.

Recently we performed a double glucagon test before and after phenformin, since phenformin was reported to inhibit gluconeogenesis (Altschuld \& Kruger, 1968). As expected, the total hyperglycaemia in the second hour $\left(\Sigma_{2}\right)$ was lower after phenformin than before phenformin (Verhaegen et al., 1970).

Ghannem et al. (1962) and Linke (1959) examined liver function by the single glucagon test and found a significant difference between patients suffering from liver diseases and normal persons. However, the great overlapping invalidated the value of the test. As the double glucagon test offers a larger spreading of the values with a different course according to various diagnostic categories it seems to possess a higher absolute and differential diagnostic value.

The test does not appear to be sufficiently informative for assessing the severity of cirrhosis as patients with well compensated cirrhosis generally presented abnormal values and the one patient with advanced alcoholic cirrhosis had a normal response.

Figure $1 \mathrm{C}$ shows that the results are widely divergent in cases of obstructive jaundice and hepatitis.

In the patients with obstructive jaundice and in those with cholelithiasis the pattern was very similar to that of the control population. Furthermore, the three patients with long-standing obstructive jaundice displayed clearly pathological serum flocculation tests and transaminases although the double glucagon test was unaffected.
All the patients with infective hepatitis displayed considerably divergent results from those of the control group. In many of these patients, the double glucagon test was repeated after a few weeks. The pattern remained abnormal until 6 weeks after the onset of the disease, although by this time all other biochemical parameters had returned to normal.

The follow-up studies are of too short a duration to establish whether the double glucagon test is effective for differentiating between patients in whom hepatitis develops into chronic hepatitis and those in whom the disease develops into cirrhosis.

Our results offer strong evidence for the value of the double glucagon test in the differential diagnosis of liver cell impairment and obstruction.

\section{Acknowledgments}

We are most grateful for the valuable help by Miss V. Schuermans. We thank Mr H. Pauwels for the technical assistance and Novo Industries, $\mathrm{A} / \mathrm{V}$, Copenhagen for supplying the glucagon.

\section{References}

Altschuld, R.A. \& Kruger, F.A. (1968) Inhibition oft hepatic gluconeogenesis in guinea-pig by phenformino $\bar{D}$ Annals of the New York Academy of Sciences, 148, 612.

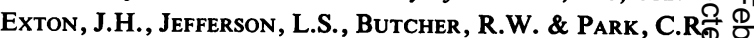
(1966) Gluconeogenesis in the perfused liver. The effect? of fasting, alloxan diabetes, glucagon, epinephrine, adeno 일 sine $3^{1}, 5^{1}$-monophosphate and insulin. American Journat of Medicine, 40, 709.

Ghannem, M.H., Said, M., Habbib, M., A-L Ghalid BUTTERFIELD, W.J. (1962) Glucagon infusion test in bilē harzial hepatic fibrosis. Guy's Hospital Reports, III, 321?

LiNKe, A. (1959) Uber die Glukagon-Probe bei Leberkrankheiten und bei Diabetes Mellitus. Klinische Wochenschrift, 37, 876.

Nelson, N. (1944) A photometric adaptation of the Somogyi method for the determination of glucose. Journal of Biological Chemistry, 153, 375.

Sutherland, E.W. \& Cori, C.F. (1951) Effect of hyperglycemic-glycogenolytic factor and epinephrine on liver phosphorylase. Journal of Biological Chemistry, 188, 531.

VaN Itally, T.B. \& Bentley, W.B. (1955) Glucagoninduced hyperglycemia as an index of liver function. Journal of Clinical Investigation, 34, 1730.

Verhaegen, H., De Beukelaer, A., Krug, F. \& VerhaegenDeClerCQ, M.L. (1970) Glucagon en diabetes. Proceedings of the Antwerpse Geneeskundige Dagen. (In press.) 